Research article

\title{
Lipoprotein profile in older patients with vascular dementia and Alzheimer's disease
}

\author{
Giovanni Zuliani*1,2, Alessandro Ble'1, Rosanna Zanca', \\ Maria Rosa Munari ${ }^{3}$, Amedeo Zurlo ${ }^{2,4}$, Chella Vavalle ${ }^{1}$, Anna Rita Atti ${ }^{1}$ and \\ Renato Fellin 1,2
}

\begin{abstract}
Address: ${ }^{1}$ Department of Clinical and Experimental Medicine, Section of Internal Medicine II, University of Ferrara, Italy, ${ }^{2}$ Centro Esperto Malattia di Alzheimer-Perusini, Ferrara, Italy, ${ }^{3}$ Long Term Division, Ca' Foncello Hospital, Treviso, Italy and ${ }^{4}$ Geriatric Division, S. Anna Hospital, Ferrara, Italy

E-mail: Giovanni Zuliani* - gzuliani@hotmail.com; Alessandro Ble' - flr@ifeuniv.it; Rosanna Zanca - flr@ifeuniv.it; Maria Rosa Munari - flr@ifeuniv.it; Amedeo Zurlo - flr@ifeuniv.it; Chella Vavalle - flr@ifeuniv.it; Anna Rita Atti - flr@ifeuniv.it; Renato Fellin - flr@ifeuniv.it

*Corresponding author
\end{abstract}

Published: 17 December 2001

Received: 2I August 200 I

BMC Geriatrics 200I, I:5

Accepted: 17 December 2001

This article is available from: http://www.biomedcentral.com//47I-23/8/I/5

(c) 200I Zuliani et al; licensee BioMed Central Ltd. Verbatim copying and redistribution of this article are permitted in any medium for any non-commercial purpose, provided this notice is preserved along with the article's original URL. For commercial use, contact info@biomedcentral.com

\begin{abstract}
Background: Some alterations of the lipoprotein profile have been associated with cerebrovascular disease. Recently, it has been suggested that cerebrovascular disease might play a role in the pathogenesis of both vascular dementia (VD) and Alzheimer's disease (AD). Nevertheless, the possible association of dyslipidemias with VD or AD is still a controversial issue.

Methods: We investigated the lipoprotein profile in 100 older patients with vascular dementia (VD; $n^{\circ}: 60$ ) or Late Onset Alzheimer's Disease (LOAD; $n^{\circ}: 40$ ). The patients were compared with 54 community dwelling non-demented older controls.

Results: After adjustment for functional status, blood sedimentation rate, and serum albumin levels, no differences in lipoprotein profile emerged between the three groups, with the exception of HDL-C that was lower in VD compared with controls. Low HDL-C $(<45 \mathrm{mg} / \mathrm{dL})$ was associated with VD (O.R.: 6.52, C.I. 95\%: I.42-30.70 vs controls, and 4.3I, C.I. 95\%: 0.93-19.82 vs LOAD), after multivariate adjustment. No differences in plasma lipid levels emerged between the three groups after stratification for apo E4 genotype.
\end{abstract}

Conclusions: In this cross-sectional study low HDL-C levels are associated with VD, but not with LOAD, in a sample of older subjects.

\section{Background}

Some alterations of lipoprotein profile, such as hypercholesterolemia and reduced levels of high-density lipoprotein cholesterol (HDL-C), are considered risk factors for cardiovascular disease, and pheraps for cerebro vascular disease [1-3].
In the last few years several authors have investigated the possible role of dyslipidemias in the pathogenesis of vascular dementia (VD) and Alzheimer's disease (AD); indeed, it has been recently suggested that cerebrovascular disease might play a role not only in VD but also in determining the presence and severity of $\mathrm{AD}[4]$. 
Reduced HDL-C [5,6] and apo A-I levels [7], as well as increased levels of lipoprotein (a) [7-9] have been reported in VD by some authors, but not by others $[9,10]$; furthermore, dementia "with stroke" has been associated with high levels of total (TC) and low-density lipoprotein (LDL) cholesterol in a large longitudinal survey [9]. Conflicting results have been obtained in AD: indeed, both increased and reduced TC values [11-13], HDL-C levels $[7,14,15]$, and LDL-C levels $[11,15]$ have been reported in different studies. High $\operatorname{Lp}(\mathrm{a})$ values have also been found in $\mathrm{AD}$ patients [16].

On the whole, the possible association of dyslipidemias with $\mathrm{VD}$ or $\mathrm{AD}$ is still a controversial issue, probably due to: 1) the very small number of patients included in most of the studies, and 2) the exclusion from the analysis of some important factors that might induce significant modifications in lipoprotein profile. As regards to this aspect, several conditions are known to modify plasma lipids in the elderly including age itself, gender, apoprotein E phenotype [17], impaired functional status [18], a condition of "frailty" [19], and an inflammation state [20].

In the present study we investigated the lipoprotein profile in a sample of older patients with VD or AD, and compared them with a group of older non-demented controls, before and after adjustment for some potential confounding factors.

\section{Materials and methods Subjects}

Three groups of subjects were enrolled in the present study:

1. Sixty consecutive patients with "probable" vascular dementia by the NINDS-AIREN criteria [21]. All subjects had an Hachinski ischemic score over 7 [22]. By CT scan, fourty subjects $(66.6 \%)$ had small-vessel disease, 14 $(23.4 \%)$ subjects had large-vessel disease, and $6(10 \%)$ had both small and large vessel disease.

2. Fourty consecutive patients with "probable" late-onset Alzheimer's disease (LOAD) by the NINCDS-ADRDA criteria [23].

The diagnosis of VD and LOAD was made by trained geriatricians; for neuropsychological assessment all subjects were given a battery of standardized tests.

3. Fifty four community dwelling older subjects without dementia. These subjects had a negative history for cardiovascular and thyroid disease, renal or hepatic insufficiency, and chronic inflammatory diseases. They did not follow an hypolipemic diet.
No patients with VD and LOAD, or control subjects were treated with lipid lowering drugs.

\section{Plasma lipids}

Blood samples were obtained after 12 hour overnight fasting, kept at $4^{\circ} \mathrm{C}$ for $1 \mathrm{~h}$, and centrifuged at $3000 \mathrm{rpm}$ for $10 \mathrm{~m}$ ' at $4^{\circ} \mathrm{C}$ to obtain serum or plasma. Total cholesterol (TC) and triglycerides (TG) were assayed by the Trinder method. HDL-C was determined after selective precipitation of apoprotein B-containing lipoproteins with $\mathrm{MgCl}_{2}$ phosphotungstic acid. Apoproteins A-I and B were measured by nephelometry. Low-density lipoprotein cholesterol (LDL-C) was calculated by the Friedewald equation (LDL-C: TC - TG/5 - HDL-C). Lipoprotein (a) was measured by ELISA (kit Immunozym Lp(a), Immuno, GMBH). Apo E genotype was evaluated on genomic DNA by polymerase chain reaction by the method of Hixon \& Vernier.

\section{Clinical chemistry}

Serum albumin was measured by nephelometry. Blood sedimentation rate (BSR) was determined by the Wintrobe method. BSR is typically increased during acute phase; although it is not an absolutely specific marker, it is currently utilized in literature as an acute phase indicator [24].

\section{Functional status}

Basic activities of daily living (BADLs) were measured by the Barthel index [25] with a score ranging from 0 (severe disability) to 20 (no disability).

\section{Statistical analysis}

Data are reported as mean \pm standard error (SE) or standard deviation (SD) as reported. Due to the "skewed" distribution of values, $\mathrm{Lp}(\mathrm{a})$ was expressed as median (range). The $\chi^{2}$ test was used to compare the categorical variables. Means were compared by ANOVA. ANCOVA was used to compare lipoprotein parameters including Barthel index score, blood sedimentation rate, and serum albumin levels as covariate. $\operatorname{Lp}(\mathrm{a})$ levels were compared by the Kruskal-Wallis test.

The odds ratio (VD vs $L O A D, V D$ vs $C$, and $L O A D$ vs $C$ ) was calculated by multivariate logistic regression analysis. HDL-C was transformed into a categorical variable (cutoff: $45 \mathrm{mg} / \mathrm{dL}$ ); albumin, BSR, and Barthel score were included as confounders.

Systat for Windows version 5.0, and SPSS for Windows version 7.0 statistical packages were used.

\section{Results}

The principal characteristics of the three groups are reported in table 1 . No differences emerged in age and gender 
Table I: Principal characteristics of demented (VD and LOAD) and control subjects.

\begin{tabular}{lccc}
\hline & VD & LOAD & CONTROLS \\
\hline Number & & 40 & 54 \\
Age (years) & 60 & $79.1 \pm 1.0$ & $82.2 \pm 0.8$ \\
Female gender & $81.3 \pm 0.8$ & $66 \%$ & $26.5 \pm 0.6^{*}$ \\
MMSE & $55 \%$ & $14.8 \pm 0.8$ & $18.6 \pm 0.7^{\circ}$ \\
Barthel index & $16.4 \pm 0.7$ & $10.9 \pm 1.0$ & $4.06 \pm 0.5 \wedge$ \\
Serum albumin (mg/dL) & $8.2 \pm 0.7$ & $4.01 \pm 0.48$ & $17.8 \pm 0.8 \S$ \\
BSR (mm/lh) & $3.79 \pm 0.5$ & $29.9 \pm 0.7$ & \\
\hline
\end{tabular}

VD: vascular dementia; LOAD: late onset Alzheimer's disease MMSE: mini mental status examination; BSR: blood sedimentation rate * $\mathrm{p}$ : $0.002 \mathrm{C}$ vs VD and LOAD; ${ }^{\circ} \mathrm{p}: 0.001 \mathrm{C}$ vs VD and $\operatorname{LOAD}^{\wedge} \mathrm{p}: 0.01 \mathrm{C}$ vs VD; $\S \mathrm{p}: 0.04 \mathrm{C}$ vs VD and LOAD

distribution. As expected, subjects with VD and LOAD had lower MMSE and Barthel index score compared with controls, while no differences were found between VD and LOAD. Serum albumin was lower in VD compared with controls (p: 0.01); BSR was higher in both VD and LOAD compared with controls (p: 0.04). Unadjusted lipoprotein parameters are compared in table 2 . Total and LDL cholesterol were lower in VD compared with controls (p: 0.001), while HDL-C was lower in VD compared with both LOAD (p:0.04) and controls (p: 0.001).

The prevalence of the $\varepsilon 4$ allele was $13.3 \%$ in $\mathrm{VD}, 17.5 \%$ in LOAD, and $9.2 \%$ in controls; the results reported in table 2 didn't change after stratification for the presence/absence of $\varepsilon 4$ allele (data not shown).

In table 3, the lipoprotein parameters are compared after adjustment for Barthel score, blood sedimentation rate, and serum albumin levels. No differences emerged between the three groups, with the exception of the HDL-C that was significantly lower in VD compared with controls (p: 0.04).

Low HDL-C $(<45 \mathrm{mg} / \mathrm{dL})$ was associated with VD: the odds ratio was 6.52 (C.I. 95\%: 1.42-30.70) compared with controls, and 4.31 (C.I. 95\%: 0.93-19.82) compared with LOAD, after adjustment for albumin, BSR, and Barthel score. The odds ratio for LOAD was 1.13 (C.I. 95\%: 0.24-6.26) compared with controls.

\section{Discussion}

The main result of this study is the finding of lower HDL$\mathrm{C}$ levels in patients with VD compared with controls, before and after adjustment for possible confounders.

The neglect of confounding factors is a major limitation when comparing plasma lipids among groups of older subjects; indeed, lipoprotein metabolism is influenced by a number of conditions that are typical of the elderly population. Different studies reported lower lipid levels in older subjects with comorbidity, disability, or with markers of acute phase $[18,26,27,20]$. Recently, Corti et al. [19] suggested that the consideration of indicators of poor health and markers of frailty, i.e. serum albumin and iron levels, may help to clarify the role of cardiovascular risk factors in various diseases in older subjects.

Our data are in good agreement the findings of other authors. Kurijama et al. reported lower HDL-C levels in 43 VD patients compared with controls [5], while Katzman et al. found lower HDL-C levels in older men with dementia "with a vascular component" [28]. Munckle et al. found lower HDL-C values in five VD compared with twelve LOAD patients [6], and proposed a possible role of HDL$\mathrm{C}$ in the differential diagnosis of these two forms of dementia; nevertheless, although HDL-C was slightly lower in VD versus LOAD in our sample, it was not useful in discriminating VD from LOAD.

It has not been established the possible mechanism linking low HDL-C and VD. A first possibility is that low HDL$C$ levels might be the result of the cross-sectional design of this study and of the effect of dementia on plasma lipid levels. We cannot exclude this possibility; nevertheless, if this is the case we should not observe significant differences between VD and LOAD.

A second possibility is that low HDL-C levels might be involved in the pathogenesis of VD. Many epidemiological studies have found a negative association between HDL-C levels and risk of ischemic stroke [29], but the pathogenesis of different subtypes of ischemic stroke may differ. Most of our VD patients were affected by lacunar strokes, and of consequence we might hypothesize a possible association between low HDL-C values and small vessels disease. It has been suggested that HDL particles might 
Table 2: Unadjusted lipoprotein parameters in demented (VD and LOAD) and control subjects (ANOVA).

\begin{tabular}{lccc}
\hline$(\mathbf{m g} / \mathbf{d L})$ & VD & LOAD & C \\
\hline & & & \\
TC & $193.5 \pm 63^{\circ}$ & $214.7 \pm 54$ & $237.7 \pm 47$ \\
TG & $133.4 \pm 89$ & $118.7 \pm 68$ & $130.3 \pm 50$ \\
HDL-C & $38.2 \pm 13^{* \wedge}$ & $48 \pm 12.3$ & $55.8 \pm 16$ \\
LDL-C & $120 \pm 38 \S$ & $135.4 \pm 44$ & $155.8 \pm 40.3$ \\
TC/HDL & $5.1 \pm 1.9$ & $4.5 \pm 1.6$ & $4.5 \pm 1.3$ \\
LP(a) $§$ & $16(1.2-124)$ & $17(1.5-140)$ & $21(1-142)$ \\
\hline
\end{tabular}

VD: vascular dementia; LOAD: late onset Alzheimer's disease; C: controls ${ }^{\circ}$ VD vs $C p: 0.001 ;^{*}$ VD vs $C p: 0.001 ;{ }^{\wedge}$ VD vs LOAD p: $0.04 ; \S$ VD vs C p: 0.001

Table 3: adjusted lipoprotein parameters in demented (VD and LOAD) and control subjects (Barthel score, blood sedimentation rate, and serum albumin covariates).

\begin{tabular}{lccc}
\hline $\mathbf{m g} / \mathbf{d L})$ & VD & LOAD & CONTROLS \\
\hline TC & & & \\
TG & $206.9 \pm 60$ & $208.5 \pm 46$ & $226.8 \pm 55$ \\
HDL-C & $138.4 \pm 84$ & $103.6 \pm 64$ & $126.1 \pm 54$ \\
LDL-C & $42.7 \pm 12^{\circ}$ & $47.1 \pm 11$ & $54 \pm 15$ \\
TC/HDL & $134.3 \pm 37$ & $144.6 \pm 41$ & $146.7 \pm 43$ \\
& $4.4 \pm 1.8$ & $4.9 \pm 1.4$ & $5.0 \pm 1.2$
\end{tabular}

VD: vascular dementia; LOAD: late onset Alzheimer's disease ${ }^{\circ}$ VD vs $C_{p}: 0.04$

play a role in the removal of excess cholesterol from the brain by interaction with apo E and heparan sulfate proteoglycans in the subendothelial space of cerebral microvessels [30]. It is also known that HDL particles favour endothelium dependent vasorelaxation by inhibiting the action of oxidized LDL particles [31], and interfere with induction of endothelial cell adhesion molecules [32]; these mechanisms might be involved in the pathogenesis of small vessels disease. Interestingly, Bonarek et al. recently found that, in a nested case-control study, elevated HDL-C levels were associated with a decreased risk of dementia at multivariate analysis [33]; nevertheless, in their sample the majority of subjects were affected by AD.

A second result of this study is the lack of significant differences in lipoprotein parameters when comparing LOAD patients and controls. In unadjusted analysis HDL$\mathrm{C}$ was higher in LOAD compared with VD, but this difference was no more significant after adjustment. Plasma lipids have been investigated in LOAD patients by several authors in the last few years, but on the whole the results are controversial. Our data seem to confirm the findings of some authors which found no differences in TC and
LDL-C $[9,14,34]$, nor in HDL-C [9,34] levels between LOAD and controls.

\section{Conclusions}

In this cross-sectional study we found that older subjects with VD, are characterized by lower HDL-C levels compared with controls. Longitudinal studies are needed in order to elucidate the possible role of HDL particles in the pathogenesis of this disease.

\section{Competing interests}

None declared

\section{References}

I. Postiglione A, Napoli C: Hyperlipidaemia and atherosclerotic cerebrovascular disease. Curr Opin Lipidol 1995, 6:236-42

2. Lindenstrom E, Boysen G, Nyboe J: Influence of total cholesterol, high density lipoprotein cholesterol, and triglycerides on risk of cerebrovascular disease: the Copenhagen City Heart Study. BMJ 1994, 309: II-5

3. Tanne D, Yaari S, Goldbourt U: High-density lipoprotein cholesterol and risk of ischemic stroke mortality. A $2 \mathrm{I}$-year followup of $\mathbf{8 5 8 6}$ men from the Israeli Ischemic Heart Disease Study. Stroke 1997, 28:83-7

4. Snowdon DA, Greiner LH, Mortimer JA, Riley KP, Greiner PA, Markesbery WR: Brain infarction and the clinical expression of Alzheimer's disease. The nun study. JAMA 1997, 277:813-817 
5. Kuriyama M, Takahashi K, Yamano T, Hokezu Y, Togo S, Osame M, Igakura $\mathrm{T}$ : Low levels of serum apoprotein $\mathrm{Al}$ and $\mathrm{All}$ in senile dementia. Jpn J Psychitry Neurol 1994, 48:589-93

6. Munckle TJ, Roy JR: High-density lipoprotein cholesterol in differential diagnosis of senile dementia. Lancet I985, I:I I I I-I I 92

7. Kurijama M, Hokezu Y, Togo S, Nagata K, Takahashi K, Igakura T, Osame M: Serum lipids, lipoprotein, and apolipoproteins in patients with senile dementia. Nippon Ronen lgakkai Zasshi 1992, 29:559-564

8. Zuliani G, Blè A, Munari MR, Palmieri E, Donegà P, Volpato S, Bader G, Rossin P, Fellin R: Cardiovascular risk factors and lipoprotein (a) in the differential diagnosis of dementias. Arch Gerontol Geriatr 1998, Suppl. 6:539-548

9. Moroney JT, Tang MX, Berglund L, Small S, Merchant C, Bell K, Yaakov S, Mayeux R: Low density lipoprotein Cholesterol and the risk of dementia with stroke. JAMA 1999, 282:254-260

10. Giubilei F, D'Antona R, Antonini R, Lenzi GL, Ricci G, Fieschi C: Serum lipoprotein pattern variations in dementia and ischemic stroke. Acta Neurol Scand 1990, 81:84-86

II. Scacchi R, De Bernardi L, Mantuano E, Bilardo T, Donini LM, Ruggeri M, Gemma AT, Pascone R, Corbo RM: DNA polymorphysm of apolipoprotein $B$ and angiotensin I-converting enzyme genes and relationships with lipid levels in Italian patients with vascular dementia or Alzheimer's disease. Dement Geriatr Cogn Disord 1998, 9:186-190

12. Kuusisto J, Koivisto K, Mykkanen L, Helkala EL, Vanhanen M, Hanninen T, Kervinen K, Kesaniemi YA, Riekkinen PJ, Laakso M: Association between features of the insulin resistance syndrome and Alzheimer's disease independently of apolipoprotein E4 phenotype: cross selectional population based study. BMJ 1997 , 3 1 5:1045-1049

13. Notkola IL, Sulkava R, Pekkanen J, Erkinjuntti T, Ehnholm C, Kivinen P, Tuomilehto J, Nissinen A: Serum total cholesterol, apolipoprotein E epsilon 4 allele, and Alzheimer's disease. Neuroepidemiology 1998, 17:14-20

14. Jàlmàn $\mathrm{K}$, Kudchodkar $\mathrm{B}$, Murray $\mathrm{K}$, McConathy $\mathrm{W}$ J, Juhàsz $\mathrm{A}$, Janka Z, Lacko AG: Evaluation of serum-lipid-related cardiovascular risk factors in Alzheimer's disease. Dement Geriatr Cogn Disord 1999, 10:488-493

15. Kuo YM, Emmerling MR, Bisgaier CL, Essenburg AD, Lampert HC $H C$, Drumm D, Roher AE: Elevated low-density lipoprotein in Alzheimer's disease correlates with brain abeta $\mathrm{I-42}$ levels. Biochem Biophys Res Commun 1998, 252:7I I-5

16. Mooser V, Helbecque N, Miklossy J, Marcovina SM, Nicos P, Amouyel $\mathrm{P}$ : Interactions between apolipoprotein $\mathrm{E}$ and apolipoprotein(a) in patients with late onset Alzheimer's disease. Ann Intern 2000, 132:533-537

17. Bader G, Zuliani G, Kostner GM, Fellin R: Apolipoprotein E polymorphism is not associated with longevity or disability in a sample of italian octo-nonagenarians. Gerontology 1998, 44:293299

18. Zuliani G, Romagnoni F, Bollini C, Leoci V, Soattin L, Fellin R: Low levels of high density lipoprotein cholesterol are a marker of disability in the elderly Gerontology 1999, 45:317-22

19. Corti MC, Guralnik JM, Salive ME, Harris T, Ferrucci L, Glynn RJ, Havlik RJ: Clarifying the direct relation between total cholesterol levels and death from coronary heart diesease in older persons. Ann Intern Med 1997, I 26:753-760

20. Volpato S, Palmieri E, Fellin R, Zuliani G: Acute phase markers are associated with reduced plasma lipid levels in a population of hospitalized eldery patients. Gerontology 2000, 46:22-27

21. Roman GC, Tatemichi TK, Erkinjuntti T, Cummings JL, Masdeu JC, Garcia JH, Amaducci L, Orgogozo JM, Brun A, Ofman A, Moody MD, MD'Brien O, Yamaguchi T, Grafman J, Drayer BP, Bennett DA, Fisher M, Ogata Y, Kokmen E, Bermejo F, Wolf PA, Gorelich PB, Bich KL, Pajeau AK, Bell MA, De Carli C, Culebras A, Korczyn AD, Bogouslavsky J, Hartmann A, Scheinberg P: Vascular dementia: diagnostic criteria for research studies. Neurology 1993, 43:250-260

22. Hachinski VC, lliff LD, Zilhka E, Du Boulay GH, AcAllister VL, et al: Cerebral blood flow in dementia. Arch Neurol 1975, 32:632-637

23. McKhann G, Drachman D, Folstein M, Katzman R, Price D, Stadlan EM: Clinical diagnosis of Alzheimer's disease: report of the NINCDS/ADRDAwork group under the auspice of department of health and human service task force of Alzheimer's disease. Neurology 1984, 34:939-944
24. Koy A: Metabolic studies of acute phase proteins. In Mariani $G$ (ad): Pathophysiology of plasma protei metabolism. New York, Plenum Press, 198486-89

25. Mahoney FL, Barthel DW: Functional evaluation: the Barthel index. Md State Med J 1965, 14:6I-65

26. Ives DG, Bonino P, Traven ND, Kuller LH: Morbidity and mortality in rural community-dwelling elderly with low total serum cholesterol. Gerontol 1993, 48:MI03-107

27. Postiglione A, Cortese C, Fischetti A, Cicerano U, Gnasso A, Gallotta G, Grossi D, Mancini M: Plasma lipids and geriatric assestment in a very aged population of South Italy. Atherosclerosis 1989, 80:63-68

28. Katzman R, Aronson M, Fuld P, Kawas C, Brown T, Morgenstern H, Frishman W, Gidez L, Eder H, Ooi WL: Development of dementing illness in a 80 year old cohort. Ann Neurol 1989, 25:317-324

29. Postiglione A, Napoli C: Hyperlipidemia and atherosclerotic cerebrovascular disease. Curr Opin Lipidol 1995, 6:236-242

30. Mulder M, Terwell D: Possible link betwen lipid metabolism and cerebral amyloid angiopathy in Alzheimer's disease: a role for high-density lipoprotein? Haemostasis 1998, 28: 174-194

31. Matsuda Y, Hirata K, Inoue N, Suematsu M, Kawashima S, Akita H, Yokoyama M: High-density lipoprotein reverses inhibitory effect of oxidized low-density lipoprotein on endothelium-dependent arterial relaxation. Circ Res 1993, 72:1 103-9

32. Cockerill GW, Rye KA, Gamble JR, Vadas MA, Barter PJ: High-density lipoproteins inhibit cytokine-induced expression of endothelial cell adhesion molecules. Artehoscler Thromb Vasc Biol 1995, I 5:1987-1994

33. Bonarek N, Barberger-Gateau P, Letenneur L, Deschamps V, Iron A Dubroca B, Dartigues JF: Relationships between cholesterol, apolipoprotein E polymorphism and dementia: a cross-selectional analysis from the PAQUID study. Neuroepidemiology $2000,19: 14 \mid-148$

34. Caramelli P, Nitrini R, Maranhao R, Laurenco ACG, Damasceno MC, Vinagre C, Caramelli B: Increase apolipoprotin B serum concentration in Alzheimer's disease. Acta Neurol Scand 1 999, 1 00:6 I-63

Publish with BioMed Central and every scientist can read your work free of charge

"BioMedcentral will be the most significant development for disseminating the results of biomedical research in our lifetime." Paul Nurse, Director-General, Imperial Cancer Research Fund

Publish with BMC and your research papers will be:

- available free of charge to the entire biomedical community

- peer reviewed and published immediately upon acceptance

- cited in PubMed and archived on PubMed Central

- yours - you keep the copyright

Submit your manuscript here

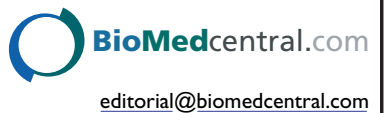

